\title{
Enhancement of win-shift radial maze retention by peripheral posttraining administration of $d$-amphetamine and 4-OH amphetamine
}

\author{
MARK G. PACKARD, CEDRIC L. WILLIAMS, and JAMES L. MCGAUGH \\ University of California, Irvine, California
}

\begin{abstract}
We examined the effect of posttraining subcutaneous injections of $d$-amphetamine and 4-OH amphetamine on acquisition of a win-shift task in an eight-arm radial maze. On each day, rats were allowed to obtain food from four randomly selected maze arms and were then removed from the maze. After a delay, the rats were returned to the maze for a retention test in which all eight arms were open and only the four arms that were not visited (i.e., win-shift) prior to the delay contained food. On the experimental day, rats were injected with drug or vehicle after completion of the first four choices, and a retention test was given after a delay of $18 \mathrm{~h}$. Posttraining injections of $1.0-\mathrm{mg} / \mathrm{kg} d$-amphetamine enhanced win-shift retention relative to the performance of saline-injected controls, while doses of $0.5 \mathrm{mg} / \mathrm{kg}$ and $2.0 \mathrm{mg} / \mathrm{kg}$ were ineffective. Posttraining injections of $4-\mathrm{OH}$ amphetamine $(2.0 \mathrm{mg} / \mathrm{kg})$, an analogue that does not readily cross the bloodbrain barrier, also enhanced win-shift retention, while doses of $0.5,1.0$, and $4.0 \mathrm{mg} / \mathrm{kg}$ had no effect. Injections of memory-enhancing doses of $d$-amphetamine and 4-OH amphetamine administered $2 \mathrm{~h}$ posttraining were ineffective. The memory enhancement observed following administration of 4-OH amphetamine suggests that peripheral actions of amphetamine may be sufficient for improving retention. However, the difference in effective doses of the two amphetamines suggests that $d$-amphetamine may enhance win-shift retention by either a direct central action or a dual action on the brain and periphery.
\end{abstract}

Peripheral posttraining injections of the indirect catecholamine agonist $d$-amphetamine have been shown to enhance memory in several aversively motivated learning and memory tasks (Doty \& Doty, 1966; Evangelista \& Izquierdo, 1971; Martinez, Jensen, et al., 1980; Martinez, Vasquez, et al., 1980). Studies of the mechanism by which $d$-amphetamine improves memory for aversive events suggest that the drug may exert its effect in part by acting on peripheral mechanisms. For example, the retention-enhancing effects of peripherally administered $d$-amphetamine obtained with inhibitory avoidance training are attenuated by adrenal medullation, and peripheral sympathectomy induced by 6-hydroxydopamine (6-OHDA) shifts the effective dose of $d$-amphetamine to a lower value (Martinez, Jensen, et al., 1980; Martinez, Vasquez, et al., 1980). In addition, intraventricular posttraining injection of a wide range of doses of $d$-amphetamine failed to enhance retention of one-trial inhibitory avoidance training (Martinez, Jensen, et al., 1980).

This research was supported by National Research Service Award 1 F32 NS08973-01 from NINDS to M.P.; by NSF Grant BNS-9006175 and a University of California Presidents Fellowship to C.L.W.; and by both USPHS Grant MH12526 from NIDA and NIMH and ONR Contract N00014-J-1626 to J.L.M. M.G.P., C.L.W., and J.L.M. are affiliated with the Center of the Neurobiology of Learning and Memory; J.L.M. is also in the Department of Psychobiology. Correspondence should be addressed to M. G. Packard, Center for the Neurobiology of Learning and Memory, University of California, Irvine, CA 92717.
Another approach to investigating the mechanism by which peripherally administered $d$-amphetamine improves memory involves the use of 4-OH amphetamine, an analog that does not readily cross the blood-brain barrier (Weiner, 1980). Peripheral posttraining injections of 4-OH amphetamine enhance retention of one-trial inhibitory avoidance (Martinez, Vasquez, et al., 1980b) and active avoidance (Martinez et al., 1983) tasks in doses that are similar to the effective doses of $d$-amphetamine. As with $d$-amphetamine, the retention-enhancing effects of 4-OH amphetamine are attenuated by adrenal medullation, and 6-OHDA-induced sympathectomy shifted the effective dose of the drug to a lower value (Martinez et al., 1983; Martinez, Vasquez, et al., 1980). Thus, several lines of evidence suggest a peripheral action for the memory-enhancing effect of peripherally administered $d$ amphetamine.

While many of the studies demonstrating memory improvement following posttraining injection of $d$ amphetamine have used aversively motivated tasks (Doty \& Doty, 1966; Evangelista \& Izquierdo, 1971; Martinez, Jensen, et al., 1980; Martinez, Vasquez, et al., 1980), comparable findings have also been obtained in studies using appetitively motivated learning tasks (Krivanek \& McGaugh, 1969; Oscos, Martinez, \& McGaugh, 1988; Packard \& White, 1989; Strupp, Bunsey, Levitsky, \& Kesler, 1991). However, the contribution of the peripheral effects of $d$-amphetamine to the memory improvement observed in appetitive tasks is unknown. To address 
this issue in the present study, we examined the effect of posttraining injections of either $d$-amphetamine or $4-\mathrm{OH}$ amphetamine on retention in a win-shift radial maze task (Packard \& White, 1989). In this task, animals are first allowed to obtain one food pellet from each of four arms in a radial maze. Following a delay, animals are returned to the maze and given access to all eight arms, but only those arms that were not entered prior to the delay contain food. Thus, the task requires animals to remember which maze arms were visited prior to the delay. On the test day, drugs are injected immediately following the first four choices, and retention is measured after a delay of $18 \mathrm{~h}$. Previous work indicates that peripheral posttraining injections of $d$-amphetamine enhance retention in this win-shift radial maze task (Packard \& White, 1989).

\section{METHOD}

\section{Subjects}

The subjects were 70 male Sprague-Dawley rats (Charles River Laboratories, $250-275 \mathrm{~g}$ ), housed individually in a temperature $\left(70^{\circ} \mathrm{F}\right)$ controlled room on a $12: 12$-h light:dark cycle (lights on from 7 a.m. to 7 p.m.). Prior to the beginning of behavioral procedures, all animals were adapted to the laboratory with ad-lib food and water for 4 days following their arrival. Behavioral testing was conducted between 1 p.m. and 5 p.m. daily.

\section{Apparatus}

The apparatus was an elevated $(60 \mathrm{~cm})$ wooden eight-arm radial maze painted flat gray. Each arm measured $60 \times 9 \mathrm{~cm}$. The center platform was $40 \mathrm{~cm}$ in diameter. Recessed food wells $(1 \times 2 \mathrm{~cm})$ were located at the end of each arm. The maze was surrounded by several extramaze cues, including horizontal and vertical striped wall posters, a 15-W lamp, a table, an animal cage rack, and the seated experimenter.

\section{Drugs}

The drugs used were $d$-amphetamine (Sigma) and dl-4-hydroxyamphetamine (Smith, Kline, \& French). The drugs were dissolved in $0.9 \%$ physiological saline prior to injection. The injections were administered subcutaneously on the dorsal surface of the neck in a volume of $1.0 \mathrm{ml} / \mathrm{kg}$. Control animals were injected with an equal volume of saline.

\section{Behavioral Procedures}

Prior to training, the animals' weights were reduced to $85 \%$ of their ad-lib feeding weights over a 5-day period. On each day, the rack of home cages was moved from the animal colony to a location in the testing room that was visually secluded from the maze; the rack remained in the testing room for the duration of the day's experimental trials. On 2 consecutive days, each animal was placed in the maze and allowed to explore for $5 \mathrm{~min}$. No food was available in the maze during the 2 habituation days, but the animals were allowed to consume 10 Noyes Formula $A$ food pellets in their home cages on each day. Food-rewarded trials began on Day 3. On each food trial, four randomly selected arms were blocked by removable Plexiglas doors and the other four were baited with a single food pellet placed in the wells of the arms. On the initial food trial only, food pellets were also placed on the center platform and on the edge of the food wells. The rat was allowed to obtain food from the four baited arms and was then removed from the maze and returned to its cage. After a delay, the animal was returned to the maze for a retention test. For the retention test, all eight arms were open and food was placed in the food wells of only the arms that had been blocked prior to the delay. The rat was removed from
Table 1

\begin{tabular}{lcrc}
\hline \multicolumn{1}{c}{ Group } & Dose $(\mathrm{mg} / \mathrm{kg})$ & $N$ & $\begin{array}{c}\text { Mean Trials } \\
\text { to Criterion }\end{array}$ \\
\hline Saline & & 20 & 10.3 \\
$d$-amphetamine & 0.5 & 7 & 10.1 \\
& 1.0 & 10 & 10.4 \\
& 2.0 & 6 & 9.8 \\
$d$-amphetamine & 1.0 & 5 & 11.0 \\
$\quad$ (delayed injection) & & & \\
4-OH amphetamine & 0.5 & 7 & 10.7 \\
& 1.0 & 7 & 11.0 \\
& 2.0 & 20 & 9.9 \\
4-OH amphetamine & 4.0 & 7 & 11.2 \\
(delayed injection) & 2.0 & 6 & 9.8 \\
\hline
\end{tabular}

the maze after the four baited arms were entered. An arm was recorded as entered when the rat reached the food cup. Records were kept of the arms entered and of the order of entry. Visits to unbaited arms on the retention test were scored as errors. The type of behavior required for accurate performance in this task has been termed win-shift since animals win by obtaining food, and must then shift to a new maze arm in order to obtain food.

There were two training phases followed by a single test (i.e., drug) trial. The delay in Phase 1 was 5 min. The delay in Phase 2 was $15 \mathrm{~min}$. To pass from one phase to the next, a rat had to make at least four correct responses on the first five retention test choices (i.e., arm entries) on 2 consecutive days. When an animal reached criterion at the 15-min delay, the test (i.e., drug) trial was given on the following day. On this trial, the animals were removed from the maze following the four predelay choices, injected immediately with drug or vehicle solutions, and then returned to their cages. The retention test was given after a delay of $18 \mathrm{~h}$. Previous findings indicate that in untreated animals trained to criterion with a 15-min delay, retention test errors increased as the test trial delay is extended from $4 \mathrm{~h}$ to $18 \mathrm{~h}$, and at the 18-h delay, the performance of control animals is essentially random (Packard \& White, 1989). This finding was the basis for the selection of the 18-h delay used on the test trial in the present study.

The treatment groups are shown in Table 1 . The animals were assigned to treatment groups by using a rank-order method as each rat reached the 15-min criterion (i.e., 1st rat to reach criterion, saline; 2nd rat, $d$-amphetamine; 3rd rat, 4-OH amphetamine; 4th rat, 4-OH amphetamine; etc.). In general, rats acquire this task at an even rate, so that several animals are tested on any given drug trial. The use of a rank-order method in assigning animals to treatment groups ensured that the mean number of trials to criterion was consistent across groups (see Table 1). An additional group of animals received a posttraining injection of $d$-amphetamine $(n=5,1.0 \mathrm{mg} / \mathrm{kg})$ or 4-OH amphetamine $(n=6,2.0 \mathrm{mg} / \mathrm{kg}), 2 \mathrm{~h}$ after the first four choices on the test trial. These doses were selected on the basis of the behavioral effects found with the immediate posttraining injections.

\section{RESULTS}

The effect of posttraining injections of $d$-amphetamine on performance on the win-shift retention test is shown in Figure 1. A one-way analysis of variance (ANOVA) of the number of errors on the retention test showed a significant group effect $[F(4,33)=6.18, p<.001]$. Scheffe's post hoc tests indicated that the $1.0-\mathrm{mg} / \mathrm{kg}$ dose of $d$-amphetamine significantly improved win-shift retention relative to saline injected controls $(F=4.53, p<$ .05 ), while doses of 0.5 and $2.0 \mathrm{mg} / \mathrm{kg}$ had no effect. In- 


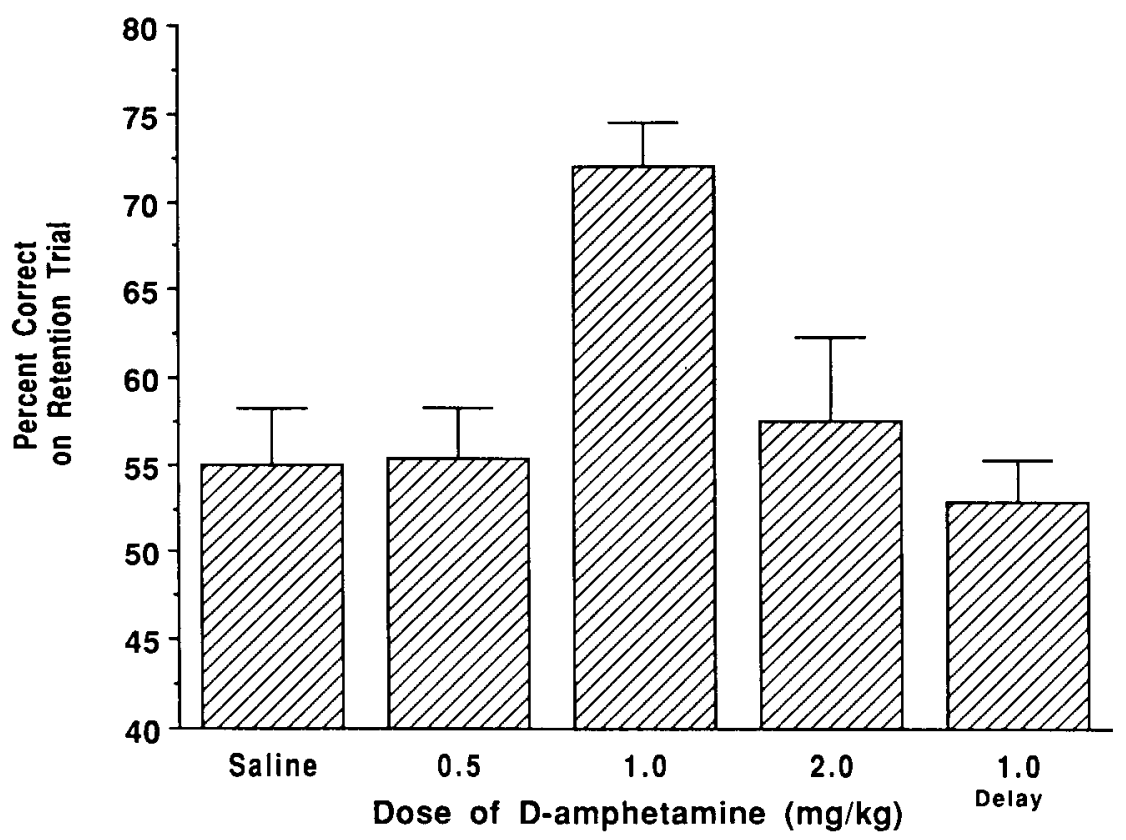

Figure 1. Effect of posttraining injection of $d$-amphetamine on win-shift retention. Animals received a posttraining injection after the first four choices in an eight-arm radial maze. The retention test was given after an 18-h delay. Percent correct $=$ number of baited arms chosen/total number of arms chosen $\times 100 \%$. Vertical bars represent the standard errors of the mean.

jections of $1.0-\mathrm{mg} / \mathrm{kg} d$-amphetamine administered $2 \mathrm{~h}$ posttraining did not affect retention (Figure 1). This finding shows that the effect of the posttraining injection of $d$-amphetamine is time dependent, indicating that the improvement in retention produced by the immediate posttraining injection was not due to a proactive effect of the drug on sensory, motoric, or motivational processes (McGaugh, 1966, 1989).

The effect of posttraining injection of 4-OH amphetamine on performance on the win-shift retention test is shown in Figure 2. In an initial experiment, a $2.0-\mathrm{mg} / \mathrm{kg}$ dose of 4-OH amphetamine $(n=10)$ produced a trend toward enhancement of retention, while doses of $0.5,1.0$, and $4.0 \mathrm{mg} / \mathrm{kg}$ had no effect. Therefore, we examined the effect of a $2.0-\mathrm{mg} / \mathrm{kg}$ dose of 4-OH amphetamine in an additional experiment by testing animals treated with saline $(n=10)$ and $4-\mathrm{OH}$ amphetamine $(n=10)$. A one-way ANOVA on the number of errors on the retention test revealed a significant group effect $[F(1,18)=4.20, p<$ $.05]$. The $2.0-\mathrm{mg} / \mathrm{kg}$ dose of $4-\mathrm{OH}$ amphetamine significantly enhanced retention. There were no significant differences between the two saline groups or the two 4-OH amphetamine groups in the two experiments, and therefore their data were combined for analysis. This accounts for the higher number of rats in these two groups (Table 1). A one-way ANOVA of the number of errors on the retention test using the combined data also showed a significant group effect $[F(4,55)=3.04, p<.05]$. Scheffé's post hoc tests indicated that the $2.0-\mathrm{mg} / \mathrm{kg}$ dose of $4-\mathrm{OH}$ amphetamine significantly improved win-shift retention relative to that of saline injected controls $(F=2.67, p<$ .05 ), while doses of $0.5,1.0$, and $4.0 \mathrm{mg} / \mathrm{kg}$ had no effect. Injections of $2.0-\mathrm{mg} / \mathrm{kg} 4-\mathrm{OH}$ amphetamine administered $2 \mathrm{~h}$ posttraining did not affect retention (Figure 2). Thus, as is the case with $d$-amphetamine, the enhancement of retention observed following immediate posttraining administration of 4-OH amphetamine is not due to a proactive effect of the drug on nonmnemonic processes.

\section{DISCUSSION}

The results indicate that peripheral posttraining administration of $d$-amphetamine enhanced retention in a win-shift radial maze task. In addition, peripheral posttraining injection of 4-OH amphetamine, an analogue with a limited capacity to cross the blood-brain barrier, also produced a significant improvement in win-shift retention.

The finding of enhancement in win-shift retention following $d$-amphetamine injection is consistent with those in previous studies using this task (Packard \& White, 1989; Strupp et al., 1991). In each of the previous studies (Martinez et al., 1983; Martinez, Jensen, et al., 1980; Martinez, Vasquez, et al., 1980; Williams \& Jensen, 1990) in which the effect of 4-OH amphetamine on memory was examined, the tasks were aversively motivated. The enhancement of win-shift retention following 4-OH amphetamine injection indicates that this effect generalizes to performance in appetitive tasks. Posttraining administration 


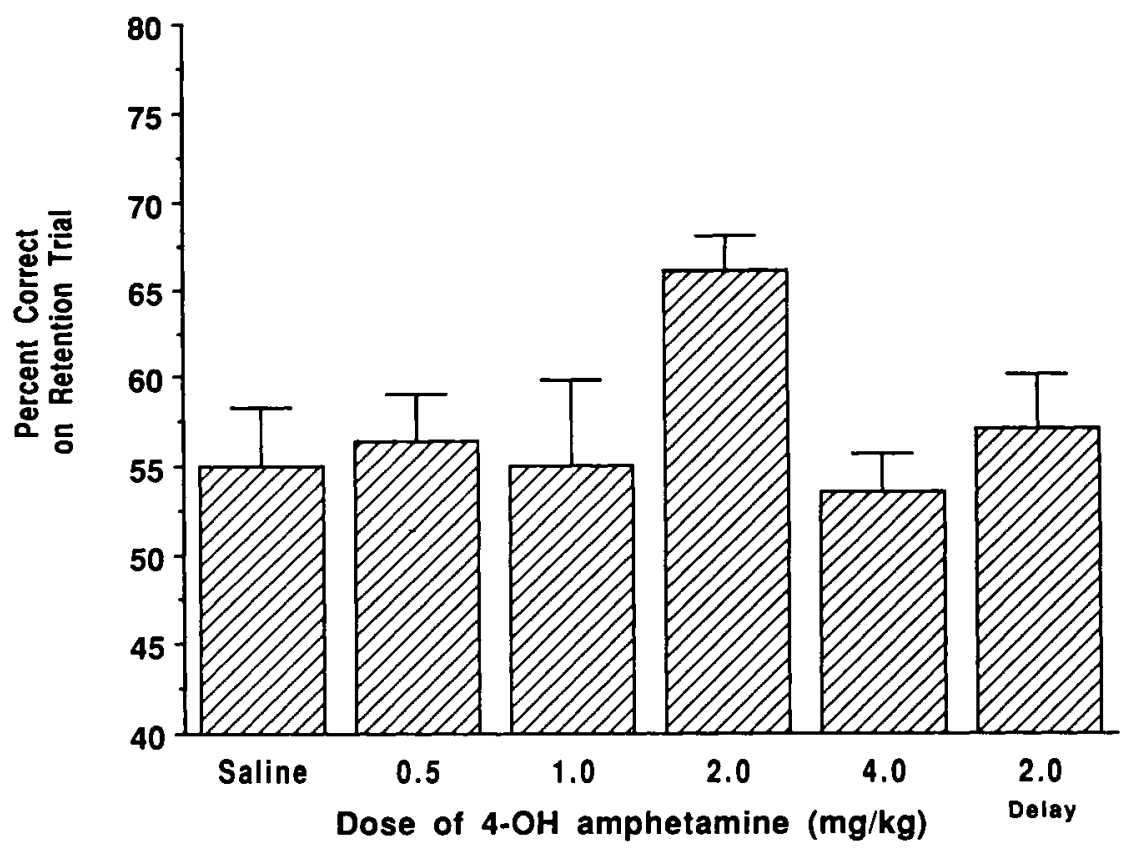

Figure 2. Effect of posttraining injection of $4-0 H$ amphetamine on win-shift retention. Animals received a posttraining injection after the first four choices in an eight-arm radial maze. The retention test was given after an 18-h delay. Percent correct = number of baited arms chosen/total number of arms chosen $\times 100 \%$. Vertical bars represent the standard errors of the mean.

of $d$-amphetamine has also been shown to be effective in enhancing memory in both aversive (e.g., Doty \& Doty, 1966; Martinez, Jensen, et al., 1980) and appetitive (Krivanek \& McGaugh, 1969; Oscos et al., 1988; Packard \& White, 1989, 1991; Strupp et al., 1991) learning tasks.

\section{Peripheral Actions of Amphetamine on Memory}

The enhancement of win-shift retention produced by 4-OH amphetamine suggests that the peripheral effects of amphetamine are sufficient to produce memory enhancement in this task. However, the precise nature of the peripherally initiated signal by which $d$-amphetamine and/or 4-OH amphetamine may act to improve memory is not well understood. One possible mechanism involves the stimulation of the adrenal medulla by $4-\mathrm{OH}$ amphetamine and $d$-amphetamine, and the subsequent release of adrenal catecholamines such as epinephrine. This action appears to contribute in part to the memory-enhancing effects of both $d$-amphetamine and 4-OH amphetamine in a one-trial inhibitory avoidance task, since these effects are attenuated by adrenal medullation (Martinez, Jensen, et al., 1980; Martinez, Vasquez, et al., 1980). Furthermore, several studies have shown that posttraining administration of epinephrine, as well as endogenous release of epinephrine from the adrenal medulla, regulates memory storage (for a review, see Gold, 1991). Increases in circulating levels of glucose, produced by epinephrine release (Ellis, Kennedy, Eusebi, \& Vincent, 1967), has been proposed as an intermediate step by which epinephrine may act, at least in part, to modulate memory storage (Gold, 1991). Consistent with this hypothesis, posttraining administration of glucose enhances memory in both aversive (Gold, 1986; Messier \& White, 1984, 1987) and appetitive (Messier \& Destrade, 1988; Packard $\&$ White, 1990) learning tasks. Moreover, unlike the effects of epinephrine (Introini-Collison, Saghafi, Novack, \& McGaugh, 1992; Stemberg, Korol, Novack, \& McGaugh, 1986), the memory-enhancing effects of glucose are not blocked by adrenergic antagonists (Hall, Vogt, $\&$ Gold, 1986). Thus, one possible peripheral mechanism by which $d$-amphetamine and 4-OH amphetamine may enhance memory involves the release of epinephrine from the adrenal medulla, with a subsequent modulatory action of glucose on memory storage.

Recent evidence indicates that the memory enhancement induced by $4-\mathrm{OH}$ amphetamine in an inhibitory avoidance task is attenuated by vagotomy (Williams \& Jensen, 1991). Vagotomy has also been shown to block the memory enhancement produced by posttraining injections of the neuropeptide CCK-8S (Flood, Smith, \& Morley, 1987). Furthermore, lesions of the celiac ganglion, which remove afferents of the right branch of the vagus nerve, block the memory-enhancing effects of posttraining administration of glucose (White, 1991). Thus, the vagus nerve is a putative pathway by which neural signals initiated in the periphery may be transmitted to regions of the central nervous system involved in memory processing.

In the present study, the dose $(2.0 \mathrm{mg} / \mathrm{kg})$ of $4-\mathrm{OH}$ amphetamine required to enhance retention was higher than the effective dose $(1.0 \mathrm{mg} / \mathrm{kg})$ of $d$-amphetamine. This 
finding contrasts with previous reports indicating that both drugs enhance memory at similar doses (Martinez, Jensen, et al., 1980; Martinez, Vasquez, et al., 1980). One possible explanation for this difference is that aversively motivated tasks were used in previous studies, and a higher dose of 4-OH amphetamine may be required to enhance memory in an appetitive task. Alternatively, the difference in effective doses of the two amphetamines may reflect the possibility that $d$-amphetamine enhances winshift retention by either a central or a dual action on the periphery and brain. In support of the latter alternative, it should be noted that due to the presence of the $l$ isomer, the racemic mixture of 4-OH amphetamine used in the present study has a slightly more potent cardiovascular action than that of $d$-amphetamine (Weiner, 1980). Thus, if $d$-amphetamine enhanced win-shift retention solely through the same peripheral mechanism as that activated by $\mathrm{dl}-4-\mathrm{OH}$ amphetamine, and if this mechanism involved amphetamine effects on cardiovascular function, one would expect that a higher dose of $d$-amphetamine would be required to enhance retention. However, the effective dose of $d$-amphetamine $(1.0 \mathrm{mg} / \mathrm{kg})$ was lower than that of dl-4-OH amphetamine $(2.0 \mathrm{mg} / \mathrm{kg})$, suggesting a possible difference in mechanism of action.

\section{Central Actions of Amphetamine on Memory}

While the ability of 4-OH amphetamine to improve retention suggests that the peripheral effects of amphetamine may be sufficient to produce memory enhancement, the findings do not rule out the possible participation, or even necessity, of the central actions of $d$-amphetamine. Although posttraining intraventricular injection of $d$ amphetamine failed to enhance retention of inhibitory avoidance training (Martinez, Jensen, et al., 1980), several recent studies have demonstrated that memory can be enhanced by intracerebral posttraining injections of $d$ amphetamine. For example, posttraining injections of $d$ amphetamine infused into the caudate nucleus improved memory in a conditioned emotional response (CER) task (Carr \& White, 1984; Viaud \& White, 1989) and in a simultaneous visual discrimination task (Packard \& White, 1991). Interestingly, the retention enhancing effect of peripheral injections of $d$-amphetamine in a CER task is blocked by 6-hydroxydopamine lesions of nigrostriatal neurons (White, 1988). One interpretation of this finding is that peripherally injected $d$-amphetamine affects memory by acting directly on dopaminergic neurons innervating the caudate nucleus. Alternatively, $d$ amphetamine may initiate a peripheral signal that subsequently acts on nigrostriatal neurons.

The findings from a previous experiment with training and test procedures identical to those of the present experiment indicate that posttraining intrahippocampal injections of $d$-amphetamine enhance win-shift retention in a radial maze task (Packard \& White, 1991). Furthermore, lesion studies have shown that the functional integrity of the hippocampal system is necessary for the acquisition of win-shift radial maze behavior (e.g., Olton, 1983). Therefore, the peripheral neural signal initiated by $4-\mathrm{OH}$ amphetamine may ultimately act on the hippocampus to produce its memory-enhancing effect. In this regard, it is interesting to note that peripheral injection of a behaviorally effective dose $(0.82 \mathrm{mg} / \mathrm{kg})$ of $4-\mathrm{OH}$ amphetamine has decreased regional brain concentrations of dopamine, but not norepinephrine, in the hippocampus, amygdala, and hypothalamus (Martinez et al., 1983).

Finally, as an indirect catecholamine agonist, $d$ amphetamine releases both dopamine and norepinephrine (Weiner, 1980). Available evidence suggests that the memory-enhancing effect of $d$-amphetamine following central administration may be due primarily to its action on dopaminergic neurons. For example, posttraining intracerebral injection of dopamine D1 (SKF-38393) and D2 (LY 171555) receptor agonists produces memory-enhancing effects comparable to those induced by $d$-amphetamine injected into the same brain regions (Packard \& White, 1991). However, further research using selective dopaminergic and noradrenergic antagonist drugs is necessary in order to evaluate the noradrenergic contribution to $d$ amphetamine-induced memory improvement.

In summary, the findings from these experiments indicate that peripheral posttraining injection of $d$-amphetamine and 4-OH amphetamine enhance retention in a win-shift radial maze task and suggest that the peripheral actions of amphetamine are sufficient to enhance memory in this task. However, the possibility that the two amphetamines act through independent mechanisms to enhance win-shift retention remains viable and is supported by the difference in effective doses of the two drugs.

\section{REFERENCES}

CARr, G. D., \& White, N. M. (1984). The relationship between stereotypy and memory improvement produced by amphetamine. Psychopharmacology, 77, 268-271.

Doty, B., \& Doty, L. A. (1966). Facilitative effects of amphetamine on avoidance conditioning in relation to age and problem difficulty. Psychopharmacologica, 9, 234-241.

Eluis, S., Kennedy, B. L., Eusebi, A. J., \& VinCent, N. H. (1967). Autonomic control of metabolism. Annals of the New York Academy of Sciences, 139, 826-832.

Evangelista, A. M., \& IzQuierdo, I. (1971). The effect of pre- and post-trial amphetamine injections on avoidance responses in the rat. Psychopharmacologica, 20, 42-47.

FLOOD, J. F., SMITH, G. E., \& Morley, J. E. (1987). Modulation of memory processing by cholecystokinin: Dependence on the vagus nerve. Science, 236, 832-834.

GoLD, P. E. (1986). Glucose modulation of memory storage processing. Behavioral \& Neural Biology, 45, 342-349.

GoLD, P. E., (1991). An integrated memory regulation system: From blood to brain. In R. C. A. Frederickson, J. L. McGaugh, \& D. L. Felten (Eds.), Peripheral signaling of the brain in neural-immune and cognitive function (pp. 391-420). New York: Hogrefe \& Huber.

Hall, J. L., VoGT, J., \& Gold, P. E. (1986). Post-training glucose effects on memory: Behavioral and pharmacological characteristics. Behavioral \& Neural Biology, 46, 145-155.

Introini-Collison, I., SAghafi, D., Novack, G. D., \& McGaugh, 
J. L. (1992). Memory-enhancing effects of post-training dipivefrin and epinephrine: Involvement of peripheral and central adrenergic receptors. Brain Research, 572, 81-86.

KrivaneK, J., \& McGaugh, J. L. (1969). Facilitating effects of preand post-training amphetamine administration on discrimination learning in mice. Agents \& Action, 1, 36-42.

Martinez, J. L., Jr., Ishikawa, K., Liang, J. C., Jensen, R. A., Bennett, C., Sternberg, D. B., \& McGaugh, J. L. (1983). 4-OH amphetamine enhances retention of an active avoidance response in rats and decreases regional brain concentrations of norepinephrine and dopamine. Behavioral Neuroscience, 97, 962-969.

Martinez, J. L., Jr., Jensen, R. A., Messing, R. B., Vasquez, B. J., Soumireu-Mourat, B., Geddes, G., Liang, K. C., McGaugh, J. L. (1980). Central and peripheral actions of amphetamine on memory storage. Brain Research, 182, 157-166.

Martinez, J. L., JR., Vasquez, B. J., Messing, R. B., Jensen, R. A., Liang, K. C., \& McGaugh, J. L. (1980). Attenuation of amphetamine-induced enhancement of learning by adrenal demedullation. Brain Research, 195, 433-443.

McGAUGH, J. L. (1966). Time-dependent processes in memory storage. Science, 153, 1351-1358.

MCGAUGH, J. L. (1989). Dissociating learning and performance: Drug and hormone enhancement of memory storage. Brain Research Bulletin, 23, 339-345.

Messier, C., \& Destrade, C. (1988). Improvement of memory for an operant response by post-training glucose in mice. Behavioral Brain Research, 31, 185-191

Messier, C., White, N. M. (1984). Contingent and non-contingent actions of sucrose and saccharin reinforcers: Effects on taste preference and memory. Physiology \& Behavior, 32, 195-203.

Messier, C., White, N. M. (1987). Memory improvement by glucose, fructose, and two glucose analogs: A possible effect on peripheral glucose transport. Behavioral \& Neural Biology, 48, 104-127.

Olton, D. S. (1983). Memory functions and the hippocampus. In W. Seifert (Ed.), Neurobiology of the hippocampus (pp. 335-373). New York: Academic Press.

Oscos, A., Martinez, J. L., JR., \& McGaugh, J. L. (1988). Effects of post-training d-amphetamine on acquisition of an appetitive autoshaped lever press response in rats. Psychopharmacology, 95, 132-134.

Packard, M. G., White, N. M. (1989). Memory facilitation pro- duced by dopamine agonists: Role of receptor subtype and mnemonic requirements. Pharmacology, Biochemistry \& Behavior, 33, 511-518.

Packard, M. G., \& Wite, N. M. (1990). Effect of posttraining injections of glucose on acquisition of two appetitive leaming tasks. Psychobiology, 18, 282-286.

PAckard, M. G., \& Wite, N. M. (1991). Dissociation of hippocampus and caudate nucleus memory systems by post-training intracerebral injection of dopamine agonists. Behavioral Neuroscience, 105 , 295-306.

Sternaerg, D. B., Korol, D. L., Novack, G. D., \& McGaugh, J. L. (1986). Epinephrine-induced memory facilitation: Attenuation by adrenergic receptor antagonists. European Joumal of Pharmacology, 129, 189-203.

Strupp, B. J., Bunsey, M., Levitsky, D., \& Kesler, M. (1991). Timedependent effects of post-trial amphetamine treatment in rats: Evidence for enhanced storage of representational memory. Behavioral \& Neural Biology, 56, 62-76.

VIAUD, M. D., \& WhITE, N. M. (1989). Dissociation of visual and olfactory conditioning in the neostriatum of rats. Behavioral Brain Research, 32, 31-42.

WEINER, N. (1980). Norepinephrine, epinephrine, and the sympathomimetic amines. In A. Goodman Gilman, L. S. Goodman, \& A. Gilman (Eds.), The pharmacological basis of therapeutics (pp. 138-176). New York: MacMillan.

WhITE, N. M. (1988). Effect of nigrostriatal dopamine depletion on the post-training, memory improving effect of amphetamine. Life Sciences, 43, 7-12.

White, N. M. (1991). Peripheral and central memory-enhancing actions of glucose. In R. C. A. Frederickson, J. L. McGaugh, \& D. L. Felten (Eds.), Peripheral signaling of the brain in neural-immune and cognitive function (pp. 421-441). New York: Hogrefe \& Huber.

Williams, C. W., \& Jensen, R. A. (1991). Vagal afferents: A possible mechanism for the modulation of peripherally acting agents. In $R$. C. A. Frederickson, J. L. McGaugh, \& D. L. Felten (Eds.), Peripheral signaling of the brain in neural-immune and cognitive function (pp. 467-472). New York: Hogrefe \& Huber.

(Manuscript received January 22, 1992; revision accepted for publication August 5, 1992.) 